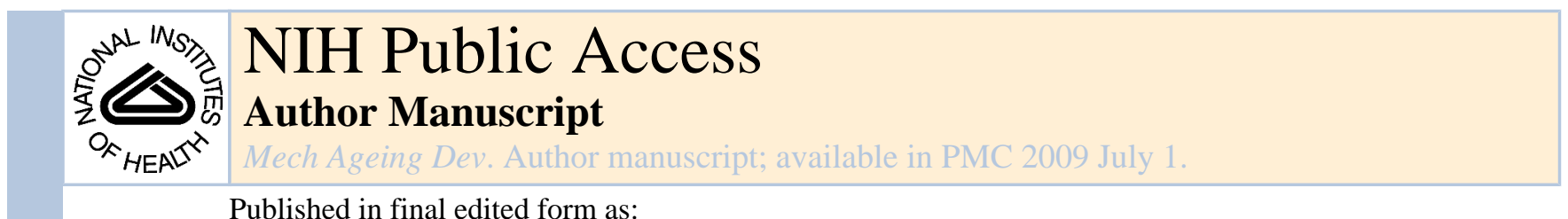

Published in final edited form as:

Mech Ageing Dev. 2008 ; 129(7-8): 383-390. doi:10.1016/j.mad.2008.03.002.

\title{
Mitochondrial DNA repair in aging and disease
}

\author{
Nadiya M. Druzhyna, Glenn L. Wilson, and Susan P. LeDoux \\ Department of Cell Biology and Neuroscience, University of South Alabama, Mobile, AL 36688
}

\section{Introduction}

Mitochondria are membrane-enclosed organelles that are found in eukaryotic cells. Often they are described as "cellular power plants", because they generate most of the cell's supply of ATP which is used as a source of chemical energy. The synthesis of ATP occurs through the respiratory or electron transport chain (ETC) which is located at the inner mitochondrial membrane and consists of five protein complexes (complex I to V). Mitochondrial respiration accounts for approximately $90 \%$ of cellular oxygen consumption. Most of the oxygen that is consumed is reduced to water through four consecutive one-electron reductions. During this process, a small proportion of the oxygen molecules (1-2\%) are converted to superoxide anion radicals. Initially, it was believed that there were two main sites of superoxide production in the respiratory chain, Complex I and Complex IV (1). However, recent studies have identified at least nine submitochondrial reactive oxygen species (ROS) generating sites (2). The superoxide that is formed then dismutates either spontaneously or enzymatically through the action of superoxide dismutase to form hydrogen peroxide (3). Hydrogen peroxide then can diffuse throughout the cell and decompose to form noxious hydroxyl radicals, which can injure the cell through interactions with macromolecules. Because of these processes, mitochondria are a major source for physiological or endogenous production of ROS. Although much attention has been focused on the harmful effects of ROS, it now has become apparent that mitochondrially-generated ROS also are involved in the regulation of intracellular signal transduction pathways leading to cellular activities such as proliferation (4). In addition to supplying ATP, mitochondria are required for numerous other cellular functions including biosynthesis of heme, cholesterol and phospholipids (5). Also, mitochondria play a major role in initiating the process of apoptosis (6).

Mitochondria are organelles which, according to the endosymbiosis theory, evolved from purpurbacteria approximately 1.5 billion years ago $(7,8)$. One of the features of mitochondria is that they have their own genome. Mitochondria replicate and transcribe their DNA semiautonomously. Like nuclear DNA, mitochondrial DNA (mtDNA) is constantly exposed to DNA damaging agents. Regarding the repair of mtDNA, the prevailing concept for many years was that mtDNA molecules suffering an excess of damage would simply be degraded to be replaced by newly generated successors copied from undamaged genomes. However, evidence now clearly shows that mitochondria contain the machinery to repair the damage to their genomes caused by certain endogenous or exogenous damaging agents. The link between mtDNA damage and repair to aging, neurodegeneration, and carcinogenesis-associated processes is the subject of this review.

\footnotetext{
*This research was supported by National Institutes of Health Grants ES03456, ES05865, NS047208, and AG19602.

Publisher's Disclaimer: This is a PDF file of an unedited manuscript that has been accepted for publication. As a service to our customers we are providing this early version of the manuscript. The manuscript will undergo copyediting, typesetting, and review of the resulting proof before it is published in its final citable form. Please note that during the production process errors may be discovered which could affect the content, and all legal disclaimers that apply to the journal pertain.
} 


\section{Mitochondrial genome}

Mitochondrial DNA comprises $0.1-2 \%$ of the total DNA in most mammalian cells. There are several very unique features of the mitochondrial genome. First, in humans, it is a circular negatively supercoiled double-stranded molecule that is $16,569 \mathrm{bp}$ long. It encodes two rRNAs, 22 tRNAs and 13 polypeptides, of which seven are components of Complex I (NADH dehydrogenase), three are components of Complex IV (cytochrome c oxidase), two are subunits of Complex V (ATP synthase) and cytochrome b (a subunit of Complex III) (11). The rest of the polypeptides of the ETC complexes, including all the subunits of Complex II (succinate dehydrogenase), as well as approximately 1500 other proteins which function in mitochondria are encoded by nuclear genes, synthesized in the cytosol and imported into mitochondria through various protein import systems. Second, genetic information is not distributed equally on the two mtDNA strands. The two mtDNA strands can be separated by denaturing cesium chloride gradient centrifugation (9). Most of the information is encoded in the heavy (purinerich) strand. The light (pyrimidine-rich) strand contains genetic information for only one polypeptide and 8 tRNAs. Third, mitochondrial genes have no introns and intergenic sequences are absent or limited to a few bases. Some genes overlap and in some instances, termination codons are not encoded (10). Fourth, the inheritance of mtDNA is almost exclusively maternal, although some important exceptions have been reported (11-13). Fifth, mitochondria do not have histones. However, mammalian mtDNA is organized in nucleoids, which can be seen under the microscope as punctuate structures containing mtDNA and proteins which localize to the matrix surface of the mitochondrial inner membrane. Mitochondrial DNA binding proteins such as transcriptional factor A (TFAM), mtSSB (mitochondrial single stranded DNAbinding protein) and Twinkle have been shown to colocalize with mtDNA in intramitochondrial foci in live cells (14). The molecular structure of the nucleoid has only partially been elucidated for yeast and much less is known about its mammalian counterpart.

Another important piece of information about mtDNA is that this genome is totally dependent upon nuclear-encoded proteins for its maintenance and transcription. Regarding replication, mtDNA replicates throughout the lifespan of an organism in both proliferating and post-mitotic cells in order to maintain a constant supply of genetic material so that mitochondria can undergo continuous turnover. The mean lifetime of a mtDNA molecule has been estimated to be 2 and 4 weeks in rat liver and brain cells respectively (15). Replication of mtDNA is conducted by DNA polymerase gamma (DNA pol $\gamma$ ). Among the 16 known eukaryotic DNA polymerases, DNA pol $\gamma$ is the only one to have been detected in mammalian mitochondria (16). According to the strand-asymmetric model, mtDNA replication occurs bi-directionally, being initiated at two spatially and temporally distinct origins of replications $\mathrm{OH}$ and $\mathrm{OL}$, for the heavy and light strands respectively (17). However, this paradigm recently has been challenged, and evidence exists which suggests the presence of conventional duplex mtDNA replication intermediates, indicative of coupled leading and lagging-strand DNA synthesis (18).

\section{Mitochondrial DNA damage and repair}

Mitochondrial DNA, just like its counterpart in the nucleus, is constantly exposed to damaging agents such as ionizing radiation, environmental toxins, as well as many therapeutic drugs. Mitochondrial DNA suffers damage from toxic chemicals to a greater extent than does nuclear DNA (19). Because the mitochondrial membrane potential generates a negative charge on the matrix-side of the inner membrane, lipophilic cations tend to accumulate in mitochondria, specifically in mitochondrial membranes. Mitochondria import lipophilic cations from the cytosol and concentrate them up to 1000-fold (20). Many drugs and biologically toxic chemicals are lipophilic and have positive charges and are thus concentrated in mitochondria and are a threat to mitochondrial components. For example, mtDNA is modified by alkylating agents at least 10-fold more than is nuclear DNA (nDNA) (19). 
Mitochondrial DNA is vulnerable to oxidative damage from both exogenous and endogenous ROS due to its proximity to the ETC, and to the lack of protective histones (21). Oxidative damage to mtDNA may be in the form of base modifications, abasic sites and various other types of lesions (22). One of the most studied lesions is 8-oxoguanine (8-oxoG), which is formed by a variety of oxidative treatments. 8-oxoG has been found to be a mutagenic lesion. Mispairing of 8-oxoG with adenine results in a G-C to T-A transversion during the subsequent round of replication. Early studies, using HPLC-electrochemical detection of the 8-oxoG, described 16-fold higher levels of 8-oxoG in mtDNA than in nDNA (23). Further studies revealed that 8-oxoG accumulates with age in nDNA and to a greater extent in mtDNA (24, 21). However, others reported that the damage in mitochondria was overestimated, and its level is comparable to that of nuclear DNA $(25,26)$. In more definitive studies, Yakes and Van Houten employing the method of quantitative extended-length PCR (QXL-PCR) showed that mtDNA damage is more extensive and persists longer than nDNA damage in human cells following oxidative stress (27).

Initially, it was thought that DNA repair mechanisms were either non-existent or very inefficient in mitochondria and that damaged DNA molecules were simply degraded, and undamaged copies served as templates for new mtDNA synthesis. Such views were based on early experiments showing that UV-induced pyrimidine dimers were not repaired in mtDNA (28). However, subsequent studies have demonstrated that certain types of damage to DNA bases resulting from deamination, simple alkylation and oxidation can be efficiently repaired in mitochondria (reviewed in 29-31). Thus, the major DNA repair mechanism acting in mitochondria is base excision repair (BER) (29-34). In general, BER starts with recognition and removal of a damaged or inappropriate base by a DNA glycosylase that cleaves the Nglycosylic bond between the base and the sugar. Many glycosylases have an associated lyase activity that breaks the phosphodiester backbone $3^{\prime}$ to the abasic site. Apurinic/apyrimidinic (AP) endonuclease then cleaves the $5^{\prime}$ phosphodiester bond leaving a one-nucleotide gap. For glycosylases, like those that remove uracil, without an associated lyase activity, the action of AP endonuclease generates a deoxyribose-phosphate moiety which must be removed by the lyase activity in DNA polymerase $\gamma$ (35). In both cases the resulting 3'-hydroxyl moiety can be extended by DNA polymerase $\gamma$ and DNA ligase activity completes the repair event by joining the free DNA ends.

Mitochondrial BER has been demonstrated by numerous groups and shown to target oxidatively modified DNA bases, such as 8-oxoG and thymine glycol (29-34,36,37). DNA repair enzymes isolated from mitochondria include several types of damage-specific DNA glycosylases (36-39), AP endonuclease (40), and DNA ligase (41,42). DNA glycosylases that are expressed as nuclear and mitochondrial isoforms encoded by the same gene, include uracil DNA-glycosylase (UDG) (43), and 8-oxoG DNA glycosylase/AP lyase (OGG) (44). MUTYH (homologue of the E. coli MutY glycosylase), NTH (thymine glycol glycosylase) and OGG have been demonstrated to localize to mitochondria in rat neurons (45) and human cells (44, 46,47). Recently, it was shown that mitochondrial BER proteins are not freely soluble, but strongly associated with an inner membrane-containing particulate fraction (48). In addition to BER, there is some evidence that mitochondria possess mismatch repair activities (49); homologous recombination (50); and non-homologous end joining (51). Comprehensive lists of the repair proteins that have been isolated from mitochondria have been included in several recent reviews (52-54). However, the significance of these mtDNA repair mechanisms is still a fertile area for investigation.

\section{Mitochondrial DNA repair and aging}

There has been a long-standing debate as to whether aging is a process of damage accumulation or an ordered, programmed process that is determined by changes in gene regulation. 
Accumulation of oxidative damage is the basis of Harman's free-radical theory of aging (55, 56). One of the main sources for ROS in the cell is oxidative phosphorylation within mitochondria, so that the free-radical theory of aging is essentially a mitochondrial theory of aging. Because mtDNA is extremely vulnerable to oxidative stress, mtDNA mutations accumulate progressively during life and are directly responsible for a measurable deficiency in cellular oxidative phosphorylation activity, leading to enhanced ROS production. In turn, increased ROS production results in progressive mtDNA damage and mutagenesis, thus causing a "vicious cycle" of exponentially increasing oxidative damage and cellular dysfunction, which ultimately culminates in death.

Numerous studies have shown that mtDNA accumulates oxidative damage in an age-dependent manner in skeletal muscle (57-59), cardiac muscle (60-62), brain (63) and liver (64). Specifically, the increase in 8-oxoG levels in mtDNA with age appears to be a general phenomenon and has been reported by de Souza-Pinto et. al (65) and Hudson et. al. (66). The steady-state concentration of 8-oxoG in mtDNA, but not in nDNA, was shown to be inversely correlated with maximum lifespan in the heart and brain of mammals. Slowly aging mammals show lower 8-oxoG levels in mtDNA than rapidly aging ones (67). Persistence of this damage would be expected to cause a high mutation rate in mtDNA. Thus, it is not surprising that mutations, including deletions, duplications, and point mutations, have been found to accumulate in mtDNA in a variety of tissues during aging in humans, monkeys, and rodents (68-73) and cause a mosaic pattern of respiratory chain deficiency in pre- and post-mitotic tissues. The most frequent and best characterized age-associated mtDNA mutation is a 4977bp deletion also called the "common deletion". Point mutations in the control/D-loop region of human mtDNA accumulate in an age-dependent manner, and age-related large rearrangements of mtDNA have also reported (68). Some of these aging-associated mtDNA mutations were originally observed in the affected tissues of patients with mitochondrial diseases. It has been established that many of these mtDNA mutations start to occur after the mid-thirties and they accumulate with age. The proportions of mutated mtDNA in aging human tissues rarely exceed $1 \%$. To explain how this apparent low level of mutations can be functionally relevant in aging there are debates in the literature concerning mosaic patterns of mtDNA segregation, clonal expansion of many individual mtDNA point mutations, as well as the premise that methodological pitfalls may lead to misinterpretation of some of the results (68,74-77). A definitive explanation remains elusive.

Early studies from our laboratory showed defective repair of oxidative damage in the mitochondrial DNA from a Xeroderma pigmentosum group A cell line (78) and in a Down's syndrome patient's fibroblasts (79). Both of these diseases display some features of accelerated aging. Other authors (80) reported that mitochondrial repair of 8-oxoG is deficient in Cockayne syndrome group B; another segmental premature aging syndrome in humans. Concurrently, several studies have indicated that OGG1 activity in liver and heart mitochondrial extracts from old rats is higher compared with extracts from young animals $(65,81)$. One possible explanation for this apparent disparity was presented in the work of Szczesny et.al. (82). This study investigated the subcellular localization of OGG1 and demonstrated that although in vitro OGG1 activity rises in aged hepatocytes most of this enzyme is stuck to the outer membrane of mitochondria and could not translocate to the mitochondrial matrix (82). It also was reported that overall mitochondrial BER activities in rat cerebral cortices gradually decline with age, reaching $80 \%$ lower activity in 30-month old rats, compared with 17-day old embryos (87). This decline was attributed to a decreased expression of repair enzymes such as OGG1 and DNA pol $\gamma(83)$. A very recent publication on age-dependent alterations in mitochondrial and nuclear BER activities in five brain regions of 6-month and 18-month old mice demonstrated a significant age-dependent decrease in uracil, 8-oxoG and 5-OH-C incision activities in mitochondria from all brain regions, whereas variable patterns of changes were seen in nuclei (84). 
In many animal models, including yeast, nematodes, fruit flies, and mice, caloric restriction has been show to be a very effective environmental method of increasing lifespan. Calorie restricted rodents have a longer lifespan than their ad libitum fed counterparts (85). A recent human trial showed that caloric restriction resulted in the expected reduction in body weight and blood insulin (86). Molecular analysis of this study revealed that caloric restriction and exercise increased the expression of genes involved in nutrient sensing and mitochondrial biogenesis. Additionally, there was an increase in mitochondrial mass. Concurrently, caloric restriction decreased markers of oxidative stress. The authors suggest that caloric restriction induces biogenesis of "efficient" mitochondria as an adaptive mechanism, which in turn lowers oxidative stress (86). Dietary restriction has also been shown to be a modulator of membrane lipid peroxidation and cytosolic antioxidant status (87). Caloric restriction has been reported to lower ROS generation in brain mitochondria $(88,89)$ and prevent age-dependent accumulation of 8 -oxoG in rat brain $(90,91)$. Calorie restricted mice were used to investigate whether lifespan extension is associated with changes in mitochondrial BER activities (92). The most significant effect of caloric restriction was a reduction in uracil-initiated BER activity in brain and kidney mitochondria, while this activity in liver was maintained or perhaps slightly enhanced. The authors propose that mitochondrial polymerase $\gamma$ might be involved in regulation of mitochondrial BER activity in calorie restricted mice (92). Since polymerase $\gamma$ is the only known polymerase in mitochondria and is responsible for both repair and replication, it is reasonable to expect that it is involved in aging associated repair of mtDNA damage. Trifunovic et.al, recently developed knock-in mice that express a proof-reading deficient version of DNA pol $\gamma$ and studied these mice for mtDNA mutations and mitochondrial agerelated changes (93). They observed a three to five-fold increase in the level of point mutations and deletions in mtDNA. Clinically, these mutant mice developed progeroid symptoms such as reduced lifespan, weight loss, reduced subcuntaneous fat, osteoporosis, alopecia, kyphosis, and reduced fertility (93). Another group (94) confirmed these observations but could not detect elevated levels of ROS in their knock-out mice. However, they did find increased apoptosis in tissues with rapid cellular turnover. They suggested that the aging phenotype in these mice could be due to apoptosis, which in this case could come from decreased maintenance of mtDNA through restricted repair of replicating mtDNA (94). These findings suggest a causative link between mtDNA mutations and aging phenotypic changes in mammals and provide further proof for the mitochondrial theory of aging. However, a recent study in mice using a sensitive assay to measure the in vivo rate of change of the mitochondrial genome at a single-base pair level challenges this theory (95). Although the authors observed an 11-fold increase in mitochondrial point mutations with age, they reported that a mitochondrial mutator mouse was able to sustain a 500-fold higher mutation burden than normal mice, without any obvious features of rapidly accelerated aging (95).

Generally, all observations, mentioned above, suggest that modifications in mtDNA repair may contribute to the accumulation of DNA damage associated with aging.

\section{Mitochondrial DNA repair in neurodegeneration and cancer}

In the 1980s it was discovered that mutations in mtDNA could be pathogenic. Since that time a number of human diseases have been linked to mutations in the mitochondrial genome. Among them are common pathological states, including premature aging, cancer, diabetes mellitus, and neurodegenerative disorders. The recent release of the Mitomap (Human Mitochondrial Genome Database) lists almost 200 pathogenic point mutations, single nucleotide deletions and insertions (http://mitomap.org.). In contrast to diseases caused by mutations in nDNA, mutations in mtDNA might not be fully expressed. This is because each mammalian cell contains 100 to 1000 mitochondria, each of which carries 2 to 10 copies of mtDNA. If all of the mtDNA in a cell has a single sequence (whether mutated or normal) the cell is homoplasmic. If some of the mtDNA copies have a normal base sequence and others 
have a mutated sequence the cell is heteroplasmic. With mitochondrial diseases the concept of threshold burden has been proposed. This means that when the percentage of mutated genomes rises above a certain level, noticeable symptoms will be observed. When the percentage of mutated DNA far exceeds this threshold then an acute (and sometimes lethal) condition will be observed (96). Many mitochondrial diseases have a delayed onset and progressive course and they result in many of the same clinical manifestations that are observed in age-related diseases.

\section{Neurodegeneration}

Mitochondrial oxidative stress and accumulation of the mtDNA mutations are believed to be particularly devastating to post-mitotic, terminally differentiated cells such as neurons. Mitochondria are central components of synapses, where they provide the energy required for synaptic activities (97). Damage to mtDNA could potentially result in bioenergetics dysfunction and consequently aberrant nerve function. Neurodegenerative diseases are associated with a progressive loss of neurons through apoptosis and/or necrosis. An accumulation of mutations and deletions in mtDNA with corresponding defects in energy metabolism have been found in Parkinson's disease (PD), Alzheimer's disease (AD), amyotrophic lateral sclerosis (ALS), and Huntington's disease (HD) (98-100). As might be expected, these mutations have been correlated with an increase in oxidative damage in the brain. Elevated levels of 8-oxoG have been found in the cortex of ALS patients (101), as well as in mitochondria in the substantia nigra of PD patients (102). Although DNA damage is elevated in both nuclear and mitochondrial DNA in AD brains, mtDNA in AD brains was shown to contain between 3- to 10-fold higher levels of oxidized bases than nDNA (103). Several studies regarding BER activity in neurodegenerative disorders showed increased expression of AP endonuclease 1 (APE1) in AD cortex extracts (104); lower activity of OGG1 in nuclear extracts from AD hippocampal gyri and parahippocampal gyri (105); and increased APE1 level in the nuclear fraction in ALS motor cortex (106). A recent publication reports significant BER deficiencies in brains of AD patients due to limited DNA base damage processing by DNA glycosylases and reduced DNA synthesis capacity by DNA polymerase $\beta$ (107). Meanwhile, far less is known about how neurodegeneration is associated with alteration in the mtDNA repair pathways.

Studies of whole brain regions do not differentiate between neurons and glial cells. However, evidence from studies using cells in culture suggests that there are cell-specific differences in mtDNA repair capacity between neurons and glial cells. Treating primary rat cultures of astrocytes, oligodendrocytes, and microglia with methylnitrosourea, an alkylating agent, does not alter the amount of initial mtDNA damage, but the repair efficiency was significantly decreased in oligodendrocytes and microglia compared with astrocytes (108). Moreover, the induction of apoptosis correlated with this decrease. These studies were the first to demonstrate a cell-specific difference in repair of mtDNA damage in cells from the central nervous system (CNS), and indicated that this difference correlated with the induction of programmed cell death (108). In a similar study, Hollensworth et al. showed that after exposure to oxidative DNA damage, oligodendrocytes and microglia accumulated more mtDNA damage, and they repaired the damage less efficiently than astrocytes (109). The differential susceptibility of glial cell types to oxidative damage and apoptosis did not appear related to cellular antioxidant capacity, because astrocytes had lower total glutathione content and superoxide dismutase (SOD) activity than did oligodendrocytes and microglia (109). In a subsequent study primary cerebellar granule cells were used to determine if mitochondrial DNA repair efficiencies correlated with oxidative stress-induced apoptosis in neuronal cells (110). Primary cerebellar granule cells had increased basal levels of glutathione and APE1 and were more sensitive to oxidative stress, resulting in less efficient repair of oxidative mtDNA lesions when compared with astrocytes. Of interest, however, is that the glycosylase and APE1 activities in the neurons 
were significantly higher with a reduction in polymerase $\gamma$ activity, suggesting that the granule cells have an imbalance in the mitochondrial BER pathway. It is this imbalance which leads to the observed increase in sensitivity to oxidative stress (110). This evidence provides a link between neuronal mtDNA repair capacity and oxidative stress-related neurodegeneration.

The importance of mitochondrial BER pathways in the development of neurodegenerative disorders was shown in an in vivo study examining expression of the DNA repair enzymes in transgenic mice carrying a mutant SOD1 gene, an animal model of ALS (111). The authors observed no changes in mitochondrial OGG1 activity, but down-regulated polymerase $\gamma$ activity in mitochondria as well as upregulated nuclear OGG1 activity in spinal motor neurons in presymptomatic transgenic mice. They assumed that the early and selective impairment of DNA repair enzymes in mitochondria of spinal motor neurons makes them more vulnerable to oxidative stress, leading to the accumulation of DNA mutations and finally cell death in this animal model of ALS (111). Additionally, a previous report suggested the impairment of mtDNA repair enzymes in human ALS cases (112).

If mitochondrial DNA repair plays a specific role in oxidative stress-induced cell death, the modulation of mtDNA repair efficiency by targeting BER enzymes to mitochondria should enhance cellular defenses of CNS cells. Indeed, targeting hOGG1 to mitochondria of oligodendrocytes enhanced mtDNA repair and protected cells against caspase 9-dependent apoptosis after menadione-induced oxidative stress (113) and cytokines-mediated damage (114). Additionally, when the yeast AP endonuclease Apn1, was expressed in mitochondria of a neuronal cell line derived from rat substantia nigra, it promoted the repair of the oxidative lesions in mtDNA and enhanced the resistance to cell death following oxidative insult (115).

Thus, it can be concluded that mtDNA repair is a critical player in the response of CNS cells to genotoxic insults. Strategies to enhance the DNA repair system in mitochondria may prove useful for retarding the pathogenesis of neurodegenerative diseases.

\section{Cancer}

Over 50 years ago Warburg suggested that mitochondria are involved in carcinogenesis through respiration alterations (116). Since then somatic mutations in mitochondrial DNA have been reported in virtually all forms of cancers examined to date (117-119). Mitochondrial DNA mutations often are found in primary tumors but not in surrounding tissues. According to Carew and Huang, the main features of mtDNA mutations common to all tumor types are: (i) the majority of the mutations are base substitutions; (ii) mutations occur in all protein-coding mitochondrial genes; (iii) the D-loop region is the most frequent site of somatic mutations across most tumor types; and (iv) the mutations are homoplasmic in nature (119). Deletions of mtDNA, as well as insertion mutations, also are reported in many kinds of cancer (120). The homoplasmic nature of mutated mtDNA raises the possibility that some mutations are involved in tumorigenesis itself by affecting energy metabolism and/or ROS production. Mitochondrial DNA mutations in tumors also could be due to the effect of aging $(93,94)$. Shidara et al. showed that specific point mutations in mtDNA accelerate growth and reduce apoptosis in a variety of tumors, supporting the notion that some mtDNA mutations in tumors have functional advantages that promote tumor growth (121). Additionally, mitochondria are key players in tumor control by apoptosis. A demonstration of the physiological significance of mtDNA mutations found in cancer was provided recently by studies with transmitochondrial cybrids ("chimeric" cells in which their own mtDNA is destroyed and replaced by mtDNA from other cells). A known pathogenic mtDNA mutation in ATP6 was introduced into PC 3 cells, a prostate cancer cell line via cybrid transfer. Injection of the resulting ATP6 mutant cybrids into nude mice resulted in the generation of tumors that were seven times larger than those generated from wild type cybrids (122). In addition, the ATP6 mutant cybrid tumors generated significantly more ROS than their wild type counterparts. These findings are a part of a growing 
body of evidence which indicates that cancer cells are under increased intrinsic oxidative stress (123). Since mitochondria are the major source for ROS production in cells, the vulnerability of mtDNA to ROS-mediated damage appears to be a mechanism for amplifying ROS stress in cancer cells. Also, mitochondrial ROS may play a role in carcinogenesis. This notion is supported by the finding that mice that are heterozygous for $\mathrm{MnSOD}\left(\mathrm{MnSOD}^{+/-}\right)$have a $100 \%$ increase in tumor incidence which is accompanied by an increase in oxidative damage in nuclear and mtDNA (124).

Proper mtDNA repair mechanisms can protect cells from mutations and increased genomic instability and thus diminish the risk for the development of cancer. Some studies have observed decreased nuclear and mitochondrial hOGG1 expression in human lung cancer (125), and in a mutant rat strain that develops spontaneous hepatocellular tumors (126). The idea of imbalanced mtDNA repair pathways in cancer was tested in several studies examining the effects of over-expression of repair enzymes in mitochondria on cellular response to oxidative and alkylating agents. Previous work from our lab revealed that targeting hOGG1 to mitochondria of a HeLa cancer cell line, which exhibited limited capacity to repair oxidative damage to its mtDNA, resulted in enhanced repair of mtDNA oxidative lesions caused by menadione and, additionally, this augmented repair led to increase cellular viability following oxidative insult $(127,128)$. A recent study from another group confirmed these findings by showing that mitochondrial over-expression of hOGG1 protects $\mathrm{HeLa}$ cells from $\mathrm{H}_{2} \mathrm{O}_{2^{-}}$ induced oxidative stress, but fails to defend cells from $4 \mathrm{NQO}$ damage, a UV-mimetic agent that induces a wide range of DNA lesions (129). These lesions are mainly repaired through nucleotide excision repair, a mechanism apparently absent in mitochondria. Furthermore, targeting and over-expression of mutant hOGG1 (R229Q mutation of hOGG1, found in human leukemia that impaired hOGG1 activity) to mitochondria resulted in a reduction of both cellular viability and mtDNA integrity after oxidative damage. These authors suggested that such mutations in DNA repair enzymes in cancer may be more detrimental to cellular survival when present in the mitochondria than in nucleus (129). Kim et al. used 4NQO to test mtDNA repair capacity in head and neck carcinomas cell lines (130). They observed mtDNA damage repair deficiencies in two of three cell lines tested in response to 4NQO treatment. Based on these findings, it was suggested that an absence of efficient repair in mitochondria may confer an intrinsic susceptibility to mutation and subsequent carcinogenesis (130).

Obviously, in the case of cancer, researchers are looking for different ways to kill cancer cells. Altering DNA repair mechanisms might be another approach to push cancer cells toward death. Thus, it was shown that the expression of Exonuclease III from E.coli in mitochondria of breast cancer cells diminishes mtDNA repair capacity and cellular viability following oxidative stress (131). Targeting and over-expressing of N-methylpurine DNA glycosylase (MPG) in mitochondria of the breast cancer cell line resulted in increased mtDNA damage following treatment with the alkylating agent methyl methansulfonate, as well as increased apoptosis levels in these cells (132). These findings might have implications in combination therapy approaches; over-expression of mito-MPG and/or MPG could result in increased kill of tumor cells using lower doses of harmful alkylating agents such as temozolomide and cross-linking agents such as cisplatin (132). A recent publication reported that nuclear-targeted MPG (employing adenoviral expression system) sensitized astroglia to methylnitrosourea (133). The authors found that mitochondrial pathways of apoptosis were blocked in astrocytes, which may be responsible, in part, for resistance of astocytomas to chemotherapeutic agents (133).

The other problem yet to be overcome in cancer treatment is how to protect normal cells against harmful effects of chemotherapeutic agents and ionizing radiation treatment. Mitochondrial DNA is a vulnerable target for anticancer drugs. One reason is that the mitochondrial respiratory chain can activate redox-cycling agents and in turn the activated agents produce ROS. Additionally, mitochondria accumulate lipophilic cations, resulting in elevated levels of 
mtDNA damage as mentioned above. Therefore, mtDNA repair pathways may be crucial for alleviating some of the side effects of cancer chemotherapy. It was reported that targeting O6MeG DNA methyltransferase (MGMT) to mitochondria of breast non-tumorigenic epithelial cells protected these cells against alkylation induced cell death (134). Evidence indicates that protection of mtDNA after alkylation is equally as important as protection of nuclear DNA. Cai et al. carried out experiments with hematopoietic cell lines characterized by low repair activity for alkylation DNA damage (135). Transfection with nuclear- or mitochondrialtargeted MGMT generated resistance in these cells against the cytotoxic effects of chemotherapeutic drugs such as 2-chloroethylnitrosourea (BCNU) and temozolomide (TMZ). This effect was more dependent on mitochondrial than on nuclear MGMT, emphasizing the contribution of mtDNA repair mechanisms in cellular resistance to alkylation chemotherapy (135).

Although many associations have been made between mtDNA mutations and cancer, the exact role of mtDNA repair systems in carcinogenesis still remains to be fully elucidated.

\section{Conclusion}

The mitochondrial genome has been completely sequenced and mapped for a variety of species including human. Numerous studies have shown that mtDNA is more susceptible to various carcinogens and ROS than nDNA. Damage to mtDNA is implicated in a wide variety of common pathological states, including neurodegenerative diseases and cancer. Additionally, the accumulation of the damage in mitochondrial genomes plays a central role in the mitochondrial theory of aging. The major protective mechanism that cells use to deal with this damage is DNA repair. Mammalian mitochondria clearly posses the ability to repair endogenous damages such as abasic sites and oxidized bases through BER mechanisms. Nevertheless, studies into the mechanisms involved in mtDNA repair are limited compared to the vast amount of information that is in the literature concerning nuclear repair mechanisms. Consequently, many questions remain to be answered. Undoubtedly, future research will address such topics as: a more precise definition of the components involved in mtDNA repair; a better comprehension of how they are regulated; and a more thorough understanding of how they can malfunction to precipitate disease states and how they become altered in aging. This knowledge will be essential for the development of future therapeutic strategies to combat a variety of human pathologies.

\section{References}

1. Turrens JF. Superoxide production by the mitochondrial respiratory chain. Biosci Rep 1997;17:3-8. [PubMed: 9171915]

2. Andreyev, AYu; Kushnareva, YuE; Starkov, AA. Mitochondrial metabolism of reactive oxygen species. Biochemistry (Moscow) 2005;70(2):200-214. [PubMed: 15807660]

3. Cadenas E, Davies KJA. Mitochondrial free radical generation, oxidative stress, and aging. Free Radic Biol Med 2000;29:222-230. [PubMed: 11035250]

4. Hsu TC, Young MR, Cmarik J, Colburn NH. Activator protein 1 (AP-1)-and nuclear factor kappaB (NF-kappaB)-dependent transcriptional events in carcinogenesis. Free Radic Biol Med 2000;28:13381348. [PubMed: 10924853]

5. Bauer MF, Gempel K, Hofman S, Jaksch M, Philbrook C, Gerbitz KD. Mitochondrial disorders. A diagnostic challenge in clinical chemistry. Clin Chem Lab Med 1999;37:855-876. [PubMed: 10596952]

6. Gupta S. Molecular steps of death receptor and mitochondrial pathways of apoptosis. Life Sci 2001;69 (25-26):2957-2964. [PubMed: 11758823]

7. Dyall SD, Brown MT, Johnson PJ. Ancient invasions: from endosymbionts to organelles. Science 2004;304:253-257. [PubMed: 15073369] 
8. Embley TM, Martin W. Eukaryotic evolution, changes and challenges. Nature 2006;440:623-630. [PubMed: 16572163]

9. Kasamatsu H, Vinograd J. Replication of circular DNA in eukaryotic cells. Annu Rev Biochem 1974;43:695-719. [PubMed: 4605048]

10. Ojala D, Montoya J, Attardi G. tRNA punctuation model of RNA processing in human mitochondria. Nature (London) 1981;290:470-474. [PubMed: 7219536]

11. Kvist L, Martens J, Higuchi H, Nazarenko AA, Valchuk OP, Orell M. Evolution and genetic structure of the great tit (Parus major) complex. Proc Biol Sci 2003;270:1447-1454. [PubMed: 12965008]

12. Schwartz M, Vissing J. New patterns of inheritance in mitochondrial disease. Biochem Biophys Res Commun 2003;310:247-251. [PubMed: 14521902]

13. Gyllensten U, Wharton D, Josefsson A, Wilson AC. Parental inheritance of mitochondrial DNA in mice. Nature 1991;352:255-257. [PubMed: 1857422]

14. Garrido N, Griparic L, Jokitalo E, Wartiovaara J, van der Bliek AM, Spelbrink JN. Composition and dynamics of human mitochondrial nucleoids. Mol Biol Cell 2003;14:1583-1596. [PubMed: 12686611]

15. Gross HJ, Getz GS, Rabinowitz M. Apparent turnover of mitochondrial deoxyribonucleic acid and mitochondrial phospholipids in the tissues of the rat. J Biol Chem 1969;244:1552-1562. [PubMed: 5773057]Kasamatsu H, Vinograd J. Replication of circular DNA in eukaryotic cells. Annu Rev Biochem 1974;43:695-719. [PubMed: 4605048]

16. Graziewicz, Ma; Longley, MJ.; Copeland, WC. DNA Polymerase $\gamma$ in Mitochondrial DNA Replication and Repair. Chem Rev 2006;106:383-405. [PubMed: 16464011]

17. Taanman JW. The mitochondrial genome: structure, transcription, translation and replication. Biochim Biophys Acta 1999;1410:103-123. [PubMed: 10076021]

18. Yang MY, Bowmaker M, Reyes A, Vergani L, Angeli P, Gringeri E, Jacobs HT, Holt IJ. Biased incorporation of ribonucleotides on the mitochondrial L-strand accounts for apparent strandasymetric DNA replication. Cell 2002;111:495-505. [PubMed: 12437923]

19. Bandy B, Davidson AJ. Mitochondrial mutations may increase oxidative stress: implication for carcinogenesis and aging? Free Radic Biol Med 1990;8:523-539. [PubMed: 2193852]

20. Singer TP, Ramsay RR. Mechanism of the neurotoxicity of MPTP. An update. FEBS Lett 1990;274:18. [PubMed: 2253761]

21. Ames BN, Shigenaga MK, Hagen TM. Oxidants, antioxidants, and the degenerative diseases of aging. Proc Natl Acad Sci USA 1993;90:7915-7922. [PubMed: 8367443]

22. Cooke MS, Evans MD, Dizdaroglu M, Lunec J. Oxidative DNA damage: mechanisms, mutation, and disease. Faseb J 2003;17:1195-1214. [PubMed: 12832285]

23. Richter C, Park JW, Ames BN. Normal oxidative damage to the mitochondrial and nuclear DNA is extensive. Proc Natl Acad Sci USA 1988;85:6465-6467. [PubMed: 3413108]

24. Mecocci P, MacGarvey U, Kaufman AE, Koontz D, Schoffner JM, Wallace DC, Beal MF. Oxidative damage to mitochondrial DNA shows marked age-dependent increases in human brain. Ann Neurol 1993;34:609-616. [PubMed: 8215249]

25. Anson RM, Hudson E, Bohr VA. Mitochondrial endogenous oxidative damage has been overestimated. Faseb J 2000;14:355-360. [PubMed: 10657991]

26. Lim KS, Jeyaseelan K, Whiteman M, Jenneer A, Halliwell B. Oxidative damage in mitochondrial DNA is not extensive. Ann N Y Acad Sci 2005;1042:210-220. [PubMed: 15965065]

27. Yakes MF, Van Houten B. Mitochondrial DNA damage is more extensive and persists longer than nuclear DNA damage in human cells following oxidative stress. Proc Natl Acad Sci USA 1997;94:514-519. [PubMed: 9012815]

28. Clayton DA, Doda JN, Friedberg EC. The absence of a pyrimidine dimmer repair mechanism in mammalian mitochondria. Proc Natl Acad Sci USA 1974;71:2777-2778. [PubMed: 4212385]

29. Croteau DL, Stierum RH, Bohr VA. Mitochondrial DNA repair pathway. Mutat Res 1999;434:137148. [PubMed: 10486588]

30. LeDoux SP, Driggers WJ, Hollensworth BS, Wilson GL. Repair of alkylation and oxidative damage in mitochondrial DNA. Mutat Res 1999;434:149-159. [PubMed: 10486589] 
31. Sawyer DE, Van Houten B. Repair of DNA damage in mitochondria. Mutat Res 1999;434:161-176. [PubMed: 10486590]

32. LeDoux SP, Wilson GL, Beecham EJ, Stevnsner T, Wassermann K, Bohr VA. Repair of mitochondrial DNA after various types of DNA damage in Chinese hamster ovary cells. Carcinogenesis 1992;13:1967-1973. [PubMed: 1423864]

33. Driggers WJ, LeDoux SP, Wilson GL. Repair of oxidative damage within the mitochondrial DNA of RINr 38 cells. J Biol Chem 1993;268:2204222045.

34. Croteau DL, Bohr VA. Repair of oxidative damage to nuclear and mitochondrial DNA in mammalian cells. J Biol Chem 1997;272:25409-25412. [PubMed: 9325246]

35. Longley MJ, Prasad R, Srivastava DK, Wilson SH, Copeland WC. Identification of 5'-deoxyribose phosphate lyase activity in human DNA polymerase $\mathrm{g}$ and its role in mitochondrial base excision repair. Proc Natl Acad Sci USA 1998;95:12244-12248. [PubMed: 9770471]

36. Croteau DL, ap Rhys CM, Hudson EK, Dianov GL, Hansford RG, Bohr VA. An oxidative damagespecific endonuclease from rat liver mitochondria. J Biol Chem 1997;272:27338-27344. [PubMed: 9341184]

37. Stierum RH, Dianov GL, Bohr VA. Single-nucleotide patch base excision repair of uracil in DNA by mitochondrial protein extracts. Nucleic Acids Res 1999;27:3712-3719. [PubMed: 10471741]

38. Domena JD, Mosbaugh DW. Purification of nuclear and mitochondrial uracil-DNA glycosylase from rat liver. Identification of two distinct subcellular forms. Biochemistry 1985;24:7320-7328. [PubMed: 3910103]

39. Kang D, Nishida J, Iyama A, Nakabeppu Y, Furuichi M, Fujiwara T, Sekiguchi M, Takeshige K. Intracellular localization of 8-oxo-dGTPase in human cells, with special reference to the role of the enzyme in mitochondria. J Biol Chem 1995;270:14659-14665. [PubMed: 7782328]

40. Tomkinson AE, Bonk RT, Linn S. Mitochondrial endonuclease activities specific for apurinic/ apyrimidinic sites in DNA from mouse cells. J Biol Chem 1988;263:12532-12537. [PubMed: 2457585]

41. Pinz KG, Bogenhagen DF. Efficient repair of abasic sites in DNA by mitochondrial enzymes. Mol Cell Biol 1998;18:1257. [PubMed: 9488440]

42. Lakshmipathy U, Campbell C. The human DNA ligase III gene encodes nuclear and mitochondrial proteins. Mol Cell Biol 1999;19:3869-3876. [PubMed: 10207110]

43. Slupphaug G, Markussen FH, Olsen LC, Aasland R, Aarsaether N, Bakke O, Krokan HE, Helland DE. Nuclear and mitochondrial forms of human uracil-DNA glycosylase are encoded by the same gene. Nucleic Acids Res 1993;21:2579-2584. [PubMed: 8332455]

44. Nishioka K, Ohtsubo T, Oda H, Fujiwara T, Kang D, Sugimachi K, Nakabeppu Y. Expression and differential intracellular localization of two major forms of human 8-oxoguanine DNA glycosylase encoded by alternatively spliced OGG1 mRNAs. Mol Biol Cell 1999;10:1637-1652. [PubMed: 10233168]

45. Englander EW, Hu Z, Sharma A, Lee HM, Wu ZH, Greeley GH. Rat MYH, a glycosylase for repair of oxidatively damaged DNA, has brain-specific isoforms that localize to neuronal mitochondria. J Neurochem 2002;83:1471-1480. [PubMed: 12472901]

46. Takao M, Aburatani H, Kobayashi K, Yasui A. Mitochondrial targeting of human DNA glycosylases for repair of oxidative DNA damage. Nucleic Acids Res 1998;26:2917-2922. [PubMed: 9611236]

47. Ohtsubo T, Nishioka K, Imaiso Y, Iwai S, Shimokawa H, Oda H, Fujiwara T, Nakabeppu Y. Identification of human MutY homolog (hMYH) as a repair enzyme for 2-hydroxyadenine in DNA and detection of multiple forms of hMYH located in nuclei and mitochondria. Nucleic Acids Res 2000;28:1355-1364. [PubMed: 10684930]

48. Stuart JA, Mayard S, Hashiguchi K, Souza-Pinto NC, Bohr VA. Localization of mitochondrial DNA base excision repair to an inner membrane-associated particulate fraction. Nucleic Acid Res 2005;33 (12):3722-32. [PubMed: 16006620]

49. Mason PA, Matheson EC, Hall AG, Lightowlers RN. Mismatch repair activity in mammalian mitochondria. Nucleic Acids Res 2003;31:1052-1058. [PubMed: 12560503]

50. Thyagarajan B, Padua RA, Campbell C. Mammalian mitochondria possess homologous recombination activity. J Biol Chem 1996;271:27536-27543. [PubMed: 8910339] 
51. Coffey G, Lakshmipathy U, Campbell C. Mammalian mitochondrial extracts possess DNA endbinding activity. Nucleic Acids Res 1999;27:3348-3354. [PubMed: 10454643]

52. Larsen NB, Rasmussen M, Rasmussen LJ. Nuclear and mitochondrial DNA repair: similar pathways? Mitochondrion 2005;5:89-108. [PubMed: 16050976]

53. Mandavilli BS, Santos JH, Van Houten B. Mitochondrial DNA repair and aging. Mutat Res 2002;509:127-151. [PubMed: 12427535]

54. Stuart JA, Brown MF. Mitochondrial DNA maintenance and bioenergetics. Biochim et Biophys Acta 2006;1757:79-89.

55. Harman D. Aging: a theory based on free radical and radiation chemistry. J Gerontol 1956;11:298300. [PubMed: 13332224]

56. Harman D. Aging: overview. Ann N Y Acad Sci 2001;928:1-21. [PubMed: 11795501]

57. Katayama M, Tanaka M, Yamamoto H, Ohbayashi T, Nimura Y, Ozawa T. Deleted mitochondrial DNA in the skeletal muscle of aged individuals. Biochem Int 1991;25:47-56. [PubMed: 1772448]

58. Lee, Cm; Chung, SS.; Kaczkowski, JM.; Weindruch, R.; Aiken, JM. Multiple mitochondrial DNA deletions associated with age in skeletal muscle of rhesus monkeys. J Gerontol 1993;48:B201-B205. [PubMed: 8227987]

59. Hayakawa M, Torii K, Sugiyama S, Tanaka M, Ozawa T. Age-associated accumulation of 8hydroxydeoxyguanosine in mitochondrial DNA of human diaphragm. Biochem Biophys Res Commun 1991;179:1023-1029. [PubMed: 1898383]

60. Hayakawa M, Sugiyama S, Hattori K, Takasawa M, Ozawa T. Age-associated damage in mitochondrial DNA in humans hearts. Mol Cell Biochem 1993;119:95-103. [PubMed: 8455592]

61. Marin-Garcia J, Zoubenko O, Goldenthal MJ. Mutations in the cardiac mitochondrial DNA control region associated with cardiomyopathy and aging. J Cardiac Fail 2002;8:93-100.

62. Lai LP, Tsai CC, Su MJ, et al. Atrial fibrillation is associated with accumulation of aging-related common type mitochondrial DNA deletion mutation in human atrial tissue. Chest 2003;123:539_ 544. [PubMed: 12576378]

63. Corral-Debrinski M, Horton T, Lott MT, Shoffner JM, Beal MF, Wallace DC. Mitochondrial DNA deletions in human brain: regional variability and increase with advanced age. Nat Genet 1992;2:324329. [PubMed: 1303288]

64. Hamilton, Ml; van Remmen, H.; Drake, JA., et al. Does oxidative damage to DNA increase with age? Proc Natl Acad Sci USA 2001;98:10469-10474. [PubMed: 11517304]

65. de Souza-Pinto NC, Hogue BA, Bohr VA. DNA reapair and aging in mouse liver: 8-oxoG glycosylase avtivity increase in mitochondrial but not in nuclear extracts. Free Radical Biol Med 2001;30:916923. [PubMed: 11295534]

66. Hudson EK, Hogue BA, Souza-Pinto NC, et al. Age-associated change in mitochondrial DNA damage. Free Radical Res 1998;29:573-579. [PubMed: 10098461]

67. Barja G, Herrero A. Oxidative damage to mitochondrial DNA is inversely related to maximum life span in the heart and brain of mammals. FASEB J 2000;14:312-318. [PubMed: 10657987]

68. Wei YH, Lee HC. Oxidative sress, mitochondrial DNA mutation, and impairment of antioxidant enzymes in aging. Exp Biol Med 2002;227:671-682.

69. Cortopassi GA, Arnheim N. Detection of a specific mitochondrial DNA deletion in tissue of older humans. Nucleic Acids Res 1990;18:6927-6933. [PubMed: 2263455]

70. Soong NW, Hinton DR, Cortopassi G, Arnheim N. Mosaicism for a specific somatic mitochondrial DNA mutation in adult human brain. Nat Genet 1992;2:318-323. [PubMed: 1303287]

71. Munscher C, Rieger T, Muller-Hocker J, Kadenbach B. The point mutation of mitochondrial DNA characteristic for MERRF disease is found also in healthy people of different ages. FEBS Lett 1993;317:27-30. [PubMed: 8428629]

72. Schwarze SR, Lee CM, Chung SS, Roecker EB, Weindruch R, Aiken JM. High levels of mitochondrial DNA deletions in skeletal muscle of old rhesus monkeys. Mech Ageing Dev 1995;83:91-101. [PubMed: 8569289]

73. Khaidakov M, Heflich RH, Manjanatha MG, Myers MB, Aidoo A. Accumulation of point mutations in mitochondrial DNA of aging mice. Mutat Res 2003;526:1-7. [PubMed: 12714177] 
74. Kang D, Hamasaki N. Alterations of mitochondrial DNA in common diseases and disease states: aging, neurodegeneration, heart failure, diabetes and cancer. Curr Med Chem 2005;12:429-441. [PubMed: 15720251]

75. Singh K. Mitochondria damage checkpoint, aging, and cancer. Ann N Y Acad Sci 2006;1067:182190. [PubMed: 16803984]

76. Alberio S, Mineri R, Tiranti V, Zeviani M. Depletion of mtDNA: Syndromes and genes. Mitochondrion 2007;7:6-12. [PubMed: 17280874]

77. Berneburg M, Kamenisch Y, Krutmann J, Rocken M. “To repair or not to repair- no longer a question”: repair of mitochondrial DNA shielding against age and cancer. Exper Derm 2006;15:1005-1015. [PubMed: 17083367]

78. Driggers WJ, Grishko VI, LeDoux SP, Wilson GL. Defective repair of axidative damage in mitochondrial DNA of a Xeroderma pigmentosum group A cell line. Cancer Res 1996;56:12621266. [PubMed: 8640811]

79. Druzhyna NM, Nair RG, LeDoux SP, Wilson GL. Defective repair of oxidative damage in mitochondrial DNA in Down's syndrome. Mutat Res 1998 Nov 12;409(2):81-9. [PubMed: 9838924]

80. Stevnser T, Nyaga S, de Souza-Pinto NC, van der Horst GTJ, Gorgels TGMF, Hogue BA, Thorslund $\mathrm{T}$, Bohr VA. Mitochondrial repair of 8-oxoguanine is deficient in Cockayne syndrome group B. Oncogene 2002;21:8675-8682. [PubMed: 12483520]

81. Stevnser T, Thorslund T, de Souza-Pinto NC, Bohr VA. Mitochondrial repair of 8-oxoguanine and changes with aging. Exper Gerontol 2002;37:1189-1196. [PubMed: 12470830]

82. Szczesny B, Bhakat KK, Mitra S, Boldogh I. Age-dependent modulation of DNA repair enzymes by covalent modification and subcellular distribution. Mech Ageing Dev 2004;125:755-765. [PubMed: 15541770]

83. Chen D, Cao G, Hastings T, Feng Y, Pei W, O'Horo C, Chen J. Age-dependent decline of DNA repair activity for oxidative lesions in rat brain mitochondria. J Neurochem 2002;81:1273-1284. [PubMed: 12068075]

84. Imam SZ, Karahalil B, Hogue BA, de Souza-Pinto NC, Bohr VA. Mitochondrial and nuclear DNArepair capacity of various brain regions in mouse is altered in age-dependent manner. Neurobiol Aging 2006;27:1129-1136. [PubMed: 16005114]

85. Weindruch R, Walford RL, Fligiel S, Guthrie D. The retardation of aging in mice by dietary restriction: longevity, cancer, immunity and lifetime energy intake. J Nutr 1986;116:641-654. [PubMed: 3958810]

86. Civitarese AE, Carling S, Heilbronn LK, Hulver MH, Ukropcova B, Deutsch WA, Smith SR, Ravussin E. Calorie restriction increases muscle mitochondrial biogenesis in healthy humans. PLoS Med 2007;4(3):e76. [PubMed: 17341128]

87. Lee DW, Yu BP. Modulation of free radicals and superoxide dismutases by age and dietary restriction. Aging 1990;2:357-362. [PubMed: 1965567]

88. Barja G. Aging in vertebrebrates, and the effect of caloric restriction: a mitochondrial free radical production-DNA damage mechanism? Biol Rev Camb Philos Soc 2004;79:235-251. [PubMed: 15191224]

89. Sanz A, Gredilla R, Pamplona R, Portero-Otin M, Vara E, Tresguerres JA, Barja G. Effect of insulin and growth hormone on rat heart and liver oxidative stress in control and caloric restricted animals. Biogerontology 2005;6:15-26. [PubMed: 15834660]

90. Sohal RS, Agarwal S, Candas M, Forster MJ, Lal H. Effect of age and caloric restriction on DNA oxidative damage in different tissue of C57BL/6 mice. Mech Ageing Dev 1994;76:215-224. [PubMed: 7885066]

91. Wolf FI, Fasanella S, Tedesco B, Cavallini G, Donati A, Bergamini E, Cittadini A. Peripheral lymphocyte 8-OHdG levels correlate with age-associated increase of tissue oxidative DNA damage in Sprague-Dawley rats. Protective effects of caloric restriction. Exp Gerontol 2005;40:181-188. [PubMed: 15763395]

92. Stuart JA, Karahalil B, Hogue BA, de Souza-Pinto NC, Bohr VA. Mitochondrial and nuclear DNA base excision repair are affected differently by caloric restriction. FASEB J 2004;18:595-597. [PubMed: 14734635] 
93. Trifunovic A, Wredenberg A, Falkenberg M, et al. Premature ageing in mice expressing defective mitochondrial DNA polymerase. Nature 2004;429:417-423. [PubMed: 15164064]

94. Kujoth GC, Hiona TD, Pugh TD, et al. Mitochondrial DNA mutations, oxidative stress, and apoptosis in mammalian aging. Science 2005;309:481-484. [PubMed: 16020738]

95. Vermulst M, Bielas JH, Kujoth GC, Ladiges WC, Rabinovitch PS, Prolla TA, Loeb LA. Mitochondrial point mutations do not limit the natural lifespan of mice. Nat Genet 2007;39(4):540-543. [PubMed: 17334366]

96. Berdanier CD, Everts HB. Mitochondrial DNA in aging and degenerative disease. Mut Res 2001;475:169-184. [PubMed: 11295162]

97. Ly CV, Verstreken P. Mitochondria at the synapse. Neuroscientist 2006;12:291-299. [PubMed: 16840705]

98. DiMauro S, Schon EA. Mitochondrial respiratory-chain diseases. N Engl J Med 2003;348:26562668. [PubMed: 12826641]

99. Kang D, Hamasaki N. Alterations of mitochondrial DNA in common diseases and disease states: aging, neurodegeneration, heart failure, diabetes, and cancer. Curr Med Chem 2005;12:429-441. [PubMed: 15720251]

100. Wallace DC. A mitochondrial paradigm of metabolic and degenerative diseases, aging, and cancer: a dawn for evolutionary medicine. Annu Rev Genet. 2005

101. Bogdanov M, Brown RH, Matson W, Smart R, Hayden D, O’Donnell H, Flint BM, Cudkowicz. Increased oxidative damage to DNA in ALS patients. Free Radic Biol Med 2000;29:652-658. [PubMed: 11033417]

102. Shimura-Miura H, Hattori N, Kang D, Miyako K, Nakabeppu Y, Mizuno Y. Increased 8-oxodGTPase in the mitochondria of substantia nigral neurons in Parkinson's disease. Ann Neurol 1999;46:920-924. [PubMed: 10589547]

103. Wang H, Xiong S, Xie C, Markesbery WR, Lovell MA. Increaswd oxidative damage in nuclear and mitochondrial DNA in Alzheimer's disease. J Neurochem 2005;93:953-962. [PubMed: 15857398]

104. Davydov V, Hansen LA, Shackelford DA. Is DNA repair compromised in Alzheimer's disease. Neurobiol Aging 2003;24:953-968. [PubMed: 12928056]

105. Lovell MA, Xie C, Markesbery WR. Decreased base excision repair and increased helicase activity in Alzheimer's disease brain. Brain Res 2000;855:116-123. [PubMed: 10650137]

106. Shaijh AY, Martin LJ. DNA base-excision repair enzyme apurinic/apyrimidinic endonuclease/redox factor- 1 is increased and competent in the brain and spinal cord of individuals with amyotrophic lateral sclerosis. Neuromol Med 2002;2:47-60.

107. Weissman L, Jo DG, Sorensen M, de Souza-Pinto NC, Markesbery WR, Mattson MP, Bohr VA. Defective DNA base excision repair in brain from individuals with Alzheimer's disease and amnestic mild cognitive impairment. Nucl Acids Res 2007;35(16):5545-5555. [PubMed: 17704129]

108. LeDoux SP, Shen C, Grishko VI, Fields PA, Gard AL, Wilson GL. Glial Cell-specific Differences in Response to Alkylation Damage. Glia 1998;24:304-312. [PubMed: 9775981]

109. Hollensworth BS, Shen C, Sim JE, Spitz DR, Wilson GL, LeDoux SP. Glial Cell Type-Specific Responses to Menadione-Induced Oxidative Stress. Free Radic Biol Med 2000;28:1161-1174. [PubMed: 10889445]

110. Harrison JF, Hollensworth SB, Spitz DR, Copeland WC, Wilson GL, LeDoux SP. Oxidative stressinduced apoptosis in neurons correlates with mitochondrial DNA base excision repair pathway imbalance. Nucleic Acids Res 2005;22(14):4660-4671. [PubMed: 16107556]

111. Murakami T, Nagai M, Miyazaki K, Morimoto N, Ohta Y, Kurata T, Takehisa Y, Kamiya T, Abe K. Early decrease of mitochondrial DNA repair enzymes in spinal motor neurons of presymptomatic transgenic mice carrying a mutant SOD1 gene. Brain Res 2007;1150:182-189. [PubMed: 17434152]

112. Kikuchi H, Furuta A, Nishioka K, Suzuki SO, Nakabeppu Y, Iwaki T. Impairment of mitochondrial DNA repair enzymes against accumulation of 8-oxo-guanine in the spinal motor neurons of amyotrophic lateral sclerosis. Acta Neuropathol 2002;103:408-414. [PubMed: 11904761] 
113. Druzhyna NM, Hollensworth SB, Kelley MR, Wilson GL, LeDoux SP. Targeting Human 8Oxoguanine Glycosylase to Mitochondria of Oligodendrocytes Protects Against MenadioneInduced Oxidative Stress. Glia 2003;42:370-378. [PubMed: 12730957]

114. Druzhyna NM, Musiyenko SI, Wilson GL, LeDoux SP. Cytokines induce NO-mediated mtDNA damage and apoptosis in oligodendrocytes. Protective role of targeting 8-oxoguanine glycosylase to mitochondria. J Biol Chem 2005;280:21673-21679. [PubMed: 15811855]

115. Ho R, Rachek LI, Xu Y, Kelley MR, LeDoux SP, Wilson GL. Yeast apurinic/apyrimidinic endonuclease Apn1 protects mammalian neuronal cell line from oxidative stress. J Neurochem 2007;102:13-24. [PubMed: 17506861]

116. Warburg O. On the origin of cancer cells. Science 1956;123:309-314. [PubMed: 13298683]

117. Copeland WC, Wachsman JT, Johnson FM, Penta JS. Mitochondrial DNA alterations in cancer. Cancer Invest 2002;20:557-569. [PubMed: 12094550]

118. Modica-Napolitano J, Singh KK. Mitochondrial dysfunction in cancer. Mitochondrion 2004;4:755762. [PubMed: 16120430]

119. Carew JS, Huang P. Mitochondrial defects in cancer. Mol Cancer 2002;1:9. [PubMed: 12513701]

120. Lee HC, Yin PH, Lin JC, et al. Mitochondrial, genome instability and mtDNA, depletion in human cancers. Ann N Y Acad Sci 2005;1042:109-122. [PubMed: 15965052]

121. Shidara Y, Yamagata K, Kanamori T, et al. Positive contribution of pathogenic mutations in the mitochondrial genome to the promotion of cancer by prevention from apoptosis. Cancer Res 2005;65:1655-1663. [PubMed: 15753359]

122. Petros JA, Baumann AK, Ruiz-Pesini E, et al. mtDNA mutations increase tumorigenicity in prostate cancer. Proc Natl Acad Sci USA 2005;102:719-724. [PubMed: 15647368]

123. Pelicano H, Carney D, Huang P. ROS stress in cancer cells and therapeutic implications. Drug Resist Updat 2004;7:97-110. [PubMed: 15158766]

124. Van Remmen H, Ikeno Y, Hamilton M, Pahlavani M, Wolf N, et al. Lifelong reduction in MnSOD activity results in increased DNA damage and higher incidence of cancer but does not accelerate aging. Physiol Genomics 2003;16:29-37. [PubMed: 14679299]

125. Mambo E, Chatterjee A, Souza-Pinto NC, et al. Oxidized guanine lesions and hOGG1 activity in lung cancer. Oncogen 2005;24:4496-4508.

126. Choudhury S, Zhang R, Frenkel K, Kawamori T, Chung FL, Roy R. Evidence of alterations in base excision repair of oxidative DNA damage during spontaneous hepatocarcinogenesis in Long Evans Cinnamon rats. Cancer Res 2003;63:7704-7707. [PubMed: 14633694]

127. Dobson AW, Xu Y, Kelley MR, LeDoux SP, Wilson GL. Enhanced mtDNA Repair and Cellular Survival Following Oxidative Stress by Targeting the hOGG Repair Enzyme to Mitochondria. J Biol Chem 2000;275:37518-37523. [PubMed: 10982789]

128. Rachek LI, Grishko VI, Musiyenko SI, Kelley MR, LeDoux SP, Wilson GL. Conditional targeting of the DNA repair enzyme hOGG1 into mitochondria. J Biol Chem 2002;277:44932-7. [PubMed: 12244119]

129. Chatterjee A, Mambo E, Zhang Y, DeWeese T, Sidransky D. Targeting of mutant hogg1 in mammalian mitochondria and nucleus: effect on cellular survival upon oxidative stress. BMC Cancer 2006;6:235. [PubMed: 17018150]

130. Kim MM, Glazer CA, Mambo E, Chatterjee A, Zhao M, Sidransky D, Califano JA. Head and neck cancer cell lines exhibit differential mitochondrial repair deficiency. Oral Oncology 2006;42:201207. [PubMed: 16266817]

131. Shokolenko IN, Alexeyev MF, Robertson FM, LeDoux SP, Wilson GL. The expression of Exonuclease III from E.coli in mitochondria of breast cancer cells diminishes mitochondrial DNA repair capacity and cell survival after oxidative stress. DNA Repair (Amst) 2003;2:471-482. [PubMed: 12713808]

132. Fishel ML, Seo YR, Smith ML, Kelley MR. Imbalancing the DNA Base Excision Repair Pathway in the Mitochondria; Targeting and Overexpressing N-Methylpurine DNA Glycosylase in Mitochondria Leads to Enhanced Cell Killing. Cancer Res 2003;63:608-615. [PubMed: 12566303]

133. Harrison JF, Rinne ML, Kelley MR, Druzhyna NM, Wilson GL, LeDoux SP. Altering DNA Base Excision Repair:Use of Nuclear and Mitochondrial-Targeted N-Methylpurine DNA Glycosylase to Sensitize Astroglia to Chemotherapeutic Agents. Glia 2007;55:1416-1425. [PubMed: 17674369] 
134. Rasmussen AK, Rasmussen LJ. Targeting of O6-MeG DNA methyltransferase (MGMT) to mitochondria protects against alkylation induced cell death. Mitochondrion 2005;5:411-417. [PubMed: 16233991]

135. Cai S, Xu Y, Cooper RJ, Ferkowicz MJ, Hartwell JR, Pollok KE, Kelley MR. Mitochondrial targeting of human O6-MeG DNA methyltransferase protects against cell killing by chemotherapeutic alkylating agents. Cancer Res 2005;65(8):3319-3327. [PubMed: 15833865] 